\title{
Topologias e Tipologias Arquitetônicas
}

\author{
ARAÚJO, Aline Freitas ${ }^{1}$ \\ PANTOJA, João da Costa ${ }^{2}$ \\ FÉLIX, Érika Ferreira ${ }^{3}$ \\ RODRIGUES, Luísa Sabino ${ }^{4}$
}

${ }^{1}$ Universidade de Brasília, Brasil. freitas.alinearaujo@gmail.com

${ }^{2}$ Universidade de Brasília, Brasil. joaocpantoja@gmail.com 33niversidade de Brasília, Brasil. felix.ferreira.erika@gmail.com

${ }^{4}$ Universidade de Brasília, Brasil. lursabino@gmail.com

\section{Resumo}

As aproximações existentes entre os conceitos topológicos e a arquitetura da forma se apresentam bastante variadas e possuem algumas intersecções, sobre as quais iremos discorrer neste artigo.

Devido à necessidade do surgimento de uma nova ciência que estudasse a percepção espacia de maneira a não levar em consideração apenas a apreensão da forma em si, temos o aparecimento do conceito de topologia como sendo o estudo que envolve as relações entre o sujeito da percepção, o objeto (no caso, o espaço arquitetônico) e o meio envolvente.

O presente artigo tem por finalidade descrever as possíveis interfaces entre topologia e arquitetura, apresentando os conceitos de topologia de redes e topologia geométrica, de onde aparecerão os conceitos de operações e superfícies topológicas, além de propor uma inovadora conceituação das topologias tipológicas e singulares (não tipológicas) e suas aplicações na arquitetura, fazendo um recorte nas estruturas singulares encontradas em Brasília.

Palavras-chave: Topologia Arquitetônica, Tipologia Arquitetônica.

\section{Abstract}

Existing approaches between topology and architecture are presented quite varied and have some intersections, on which we will discuss throughout this article.

Due to the need of the emergence of a new science to study the spatial perception that it cannot take into consideration only the apprehension of form itself, there is the appearance of topology as study involving the relationship between the subject of perception, the object ( in this case, the architectural space ) and the surroundings.

This article aims to describe the possible interfaces between topology and architecture, presenting the network topology and geometric topology concepts, where will appear the operations and topological surfaces concepts, in addition to proposing an innovative concept of typological and single topology ( not typological ) and its applications in architecture, making a cut in the typological topological structures found in Brasilia.

Key-words: Architectural Topology, Architectural Typology. 


\section{Introdução}

Há muito tempo as teorias arquitetônicas se ocupam do estudo da percepção e produção do espaço. Uma vez que as teorias Gestaltistas começaram a se tornar insuficientes por abordarem um pensamento subordinado à apreensão da forma, temos o aparecimento da topologia que vai direcionar esse estudo da percepção espacial por uma abordagem que envolve o sujeito da percepção, o objeto e o meio envolvente. (CONSIGLIERI apud ABASCAL e BILBAO, 2011)

Um dos pontos de intersecção entre a topologia e a arquitetura compreende as relações entre a pessoa e o ambiente a partir da comunicação entre os espaços. É a topologia que vai conferir o caráter qualitativo da arquitetura, determinando sua singularidade. (ABASCAL e BILBAO, 2011)

Com isso, pode-se dizer que a topologia estuda as estruturas invariantes que se encontram fora do plano euclidiano, tais como: interior e exterior, perto e longe, separado e unido, contínuo e descontínuo.

Outra interface de comunicação está calcada nas características invariantes que um objeto possui apesar de ser submetido à deformações ou transformações em sua geometria.

Seria essa, talvez, a maior área de contato entre topologia e arquitetura: a capacidade de imaginação de ambientes que excedam a $3^{a}$ dimensão e sua representação em dimensões menores.

\subsection{Objetivo}

O trabalho tem por objetivo apresentar duas interfaces de intersecção entre a arquitetura e a topologia - Topologia de Redes e Topologia Geométrica - que, durante a pesquisa, tiveram maior destaque, sendo a topologia geométrica o foco principal.

Com o desenvolvimento do conceito de topologia geométrica, pretende-se discorrer a respeito das superfícies topológicas, abrindo espaço para a classificação das chamadas tipologias arquitetônicas.

\section{Conceitos}

A origem do conceito de Topologia cabe ao matemático alemão Johann Benedict Listing em 1847 em que a palavra surge, pela primeira vez, em seu livro Vorstudien zur Topologie:

"Por Topologia nós entendemos a teoria das características modais dos objetos, ou das leis de conexão, de posições relativas e de sucessão de pontos, linhas, superfícies, corpos e suas partes, ou agregados no espaço, sempre sem considerar os problemas de medidas ou quantidade." (LISTING apud SPERLING, 2003)

Em termos topológicos, tem-se duas áreas que possuem maior inter-relação tanto com a arquitetura, quanto entre si. Essas áreas são a Topologia de Redes e a Topologia Geométrica.

\subsection{Topologia de Redes}

Para o entendimento da topologia de redes fazse necessário remontar ao matemático Leonhard Euler, no século XVIII, mais especificamente à uma questão de planejamento urbano: o problema das pontes de Königsberg (Figura 1), na Prússia (atual Kaliningrado e Rússia, respectivamente). $\mathrm{Na}$ cidade, cortada pelo rio Nagel, formada por duas margens e duas ilhas centrais unidas por sete pontes, seria possível passar pelas quatro áreas, iniciando em um ponto qualquer, passando por todas as pontes apenas uma vez e voltar ao ponto inicial?

Figura 1: As 7 pontes de Königsberg

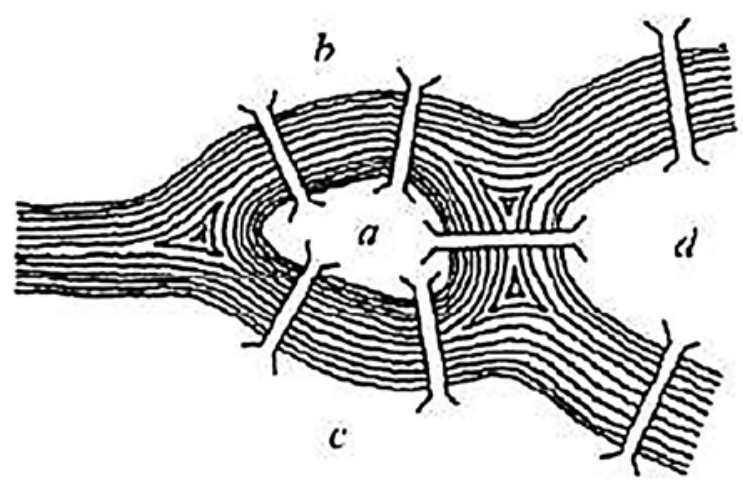

Fonte: MARCH, Lionel, STEADMAN, Philip. The Geometry of Enviornment. London: Methuen \& Co, 1971. p. 242

Para resolver o problema, Euler transformou os caminhos em retas e as intersecções em pontos, criando assim, possivelmente, o primeiro grafo (Figura 2).

Figura 2: Representação de Euler

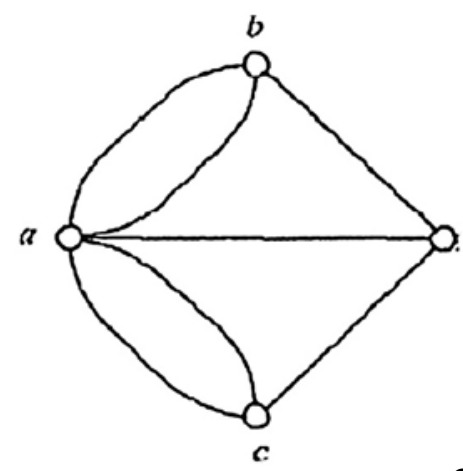

Fonte: SPERLING, David Moreno. Arquiteturas Contínuas e Topologia: similaridades em processo. São Paulo, 2003. p. 119 
O grafo aqui vai ser o protagonista da nossa história devido às suas características de guardar as relações entre os pontos mesmo que sua forma seja alterada.

Paulo Boaventura (1996), citado por SPERLING (2003), vai destacar o caráter icônico do grafo, dizendo que "a representação esquemática de grafos...apresenta a vantagem da fácil apreensão pela percepção global no que se refere a alguns de seus aspectos topológicos", ou seja, o grafo tem a capacidade de permitir uma extração direta dos dados do objeto pelo observador através de sua leitura simultânea.

As representações dadas por meio de grafos são regidas apenas por relações topológicas entre os pontos que compõem sua forma espacial.

\subsection{Topologia Geométrica}

A topologia Geométrica também remete à Euler no século XVIII, no momento em que desenvolve uma teoria que investiga as relações estruturais para compreender uma estrutura no espaço.

Ele demonstra que, por exemplo, para um cubo, com 6 faces, 12 arestas e 8 vértices, existe uma relação constante denominada número de Euler, que se define pela equação $E=F-A+V$ e é a mesma para uma pirâmide de base quadrada que possui 5 faces, 8 arestas e 5 vértices.

Isso significa que para qualquer subdivisão de uma superfície, seja ela uma deformação ou uma divisão ortogonal, o número de Euler continua sempre igual e, nesse caso, igual a 2.

Com essa constante valendo 2, cria-se então o conceito da lei das 5 cores que diz que a cada 5 porções de espaços articulados, 2 não se tocam, sendo possível a criação de mapas que obedecem à essa invariância.

Tal lei comprova que o número de Euler é um invariante topológico de superfície, ou seja, ele não depende da representação poliédrica do objeto, mas sim de sua forma topológica.

Existe ainda números de Euler diferentes de 2, como é o caso da garrafa de Klein, do toro e do plano projetivo - superfícies topológicas que serão apresentadas mais a frente. Segundo Heawood, citado por SAMPAIO (2009), nesses casos os mapas seriam pintados com um número diferente de cores. No entanto, o que temos é uma superfície não orientável, ou seja, não há possibilidade de habitação para o ser humano em superfícies desse tipo.

Portanto, seria essa a interface da topologia que, relacionada com a arquitetura, vai estudar as re- lações espaciais dos objetos que se mantêm constantes apesar de transformações ou deformações, compondo a ramificação de maior enfoque nesse trabalho.

\subsubsection{Operações Topológicas}

À topologia é mais interessante as relações dos pontos da forma do que a própria forma, de tal modo que um círculo se torna mais próximo de um triângulo ou um quadrado do que de um círculo do qual foi retirado um ponto de seu interior.

$\mathrm{O}$ ato de mudar a forma, mantendo as relações entre os pontos dessa forma é chamado de Homeomorfismo (Figura 3).

Figura 3: Homeomorfismo entre uma caneca e uma rosquinha

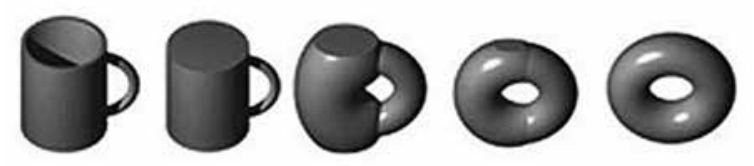

Fonte: Disponível em: http://ceciliakollross.com/

Um homeomorfismo transforma pontos do primeiro objeto que estão próximos em pontos do segundo objeto também próximos, e pontos distantes também se mantém distantes em ambos os objetos.

Essas transformações dão origem à superfícies independentes e, ao serem submetidas à cortes, aproximação e colagem de bordos, através de uma outra operação topológica chamada Soma Conexa (Figura 4), obtêm-se resultantes chamadas superfícies topológicas.

Figura 4: Soma Conexa entre um toro e um bi-toro

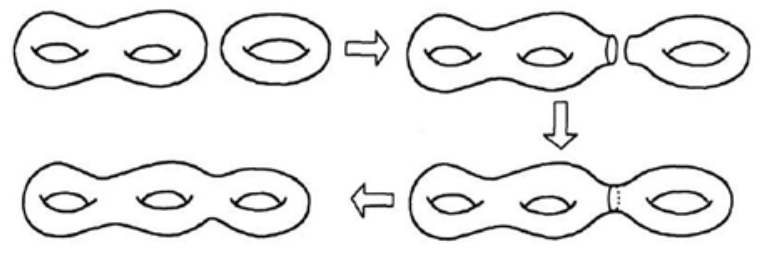

Fonte: SPERLING, David Moreno. Arquiteturas Contínuas e Topologia: similaridades em processo. São Paulo, 2003. p. 141

\subsubsection{Superfícies Topológicas}

A concepção da arquitetura com base na topologia tem se fundamentado nas superfícies não- 
orientáveis - aquelas que em seu processo de criação perdem a ideia de dentro e fora. As superfícies que compreendem maior índice de inspiração entre os arquitetos são:

\section{- FAIXA DE MÖBIUS}

A faixa de Möbius (Figura 5) é uma superfície não orientável e, apesar de ter sido apresentada por August Ferdinand Möbius em 1858, sua invenção é atribuída à Listing 20 anos antes.

Consiste em uma fita em que uma das pontas é rotacionada em $180^{\circ}$ e depois coladas suas extremidades. Nessa superfície, diferentemente de uma fita comum com suas extremidades coladas, quando se toma um ponto de início sobre uma das faces só é possível retornar ao mesmo ponto percorrendo ambas as faces da fita.

\section{Figura 5: Faixa de Möbius}

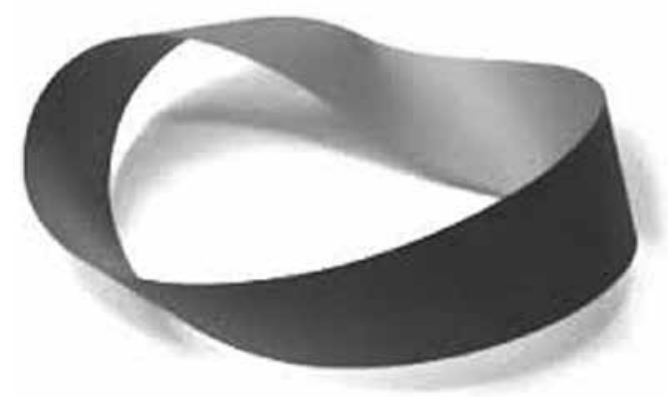

Fonte: Disponível em: http://diascaes.blogspot.com.br/

É possível encontrar diversos projetos inspirados na Faixa de Möbius - que possui apenas um lado e uma borda -, como é o caso da ponte para pedestres sobre o rio Dragon King (Figura 6), na China.

Figura 6: Ponte para pedestres

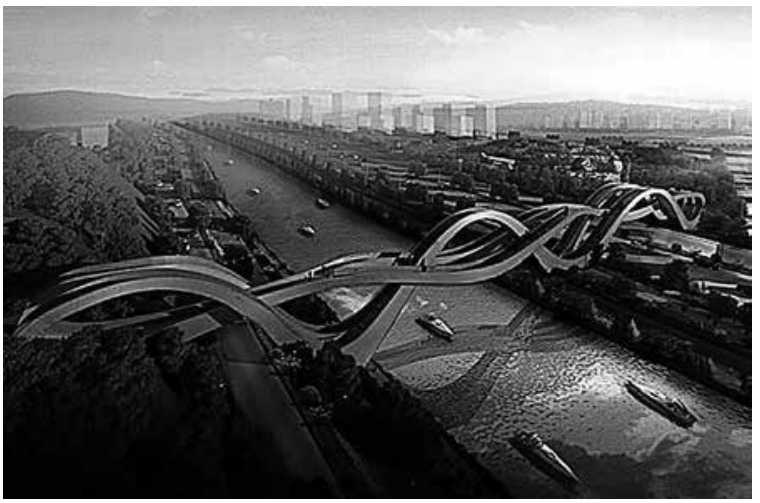

Fonte: Disponível em: http://www.bimbon.com.br/

O estúdio holandês NEXT Architects ganhou recentemente (2014) um concurso para a construção da ponte de $150 \mathrm{~m}$ de extensão.

O projeto ganha forma por uma sequência de fitas de aço que se alternam para criar a sensação de uma estrutura sem fim.

\section{- TORO}

Outra superfície de destaque - nesse caso, orientável - é o Toro (Figura 7). Geometricamente falando, o toro é um sólido de revolução gerado pela rotação de um círculo de raio $r$ em torno de um eixo coplanar de distância $\mathrm{R}$ do centro.

Figura 7: Toro

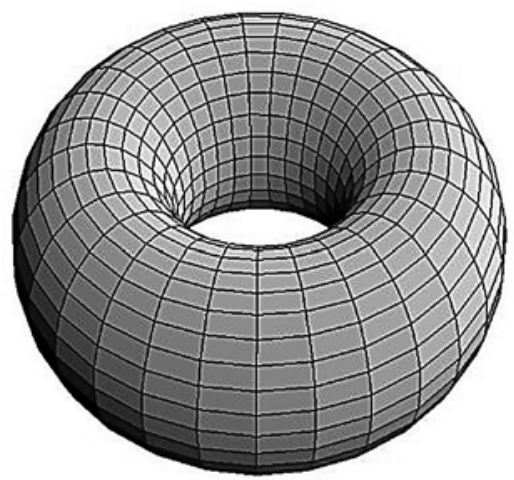

Fonte: http://culturagenerale.myblog.it/

$\mathrm{Na}$ arquitetura, o toro serviu de inspiração para um projeto da NASA (Figuras 8 e 9), elaborado entre 1925 e 1976.

Figura 8: Colônia Torus - Vista externa

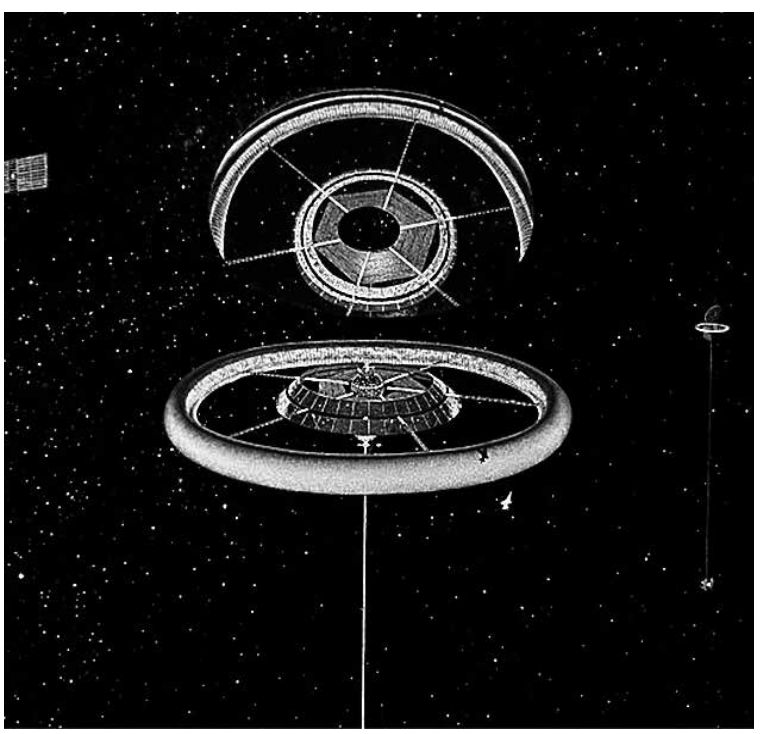

Fonte: Disponível em: http://nerdivinas.com/ 
Figura 9: Colônia Torus - Vista interna

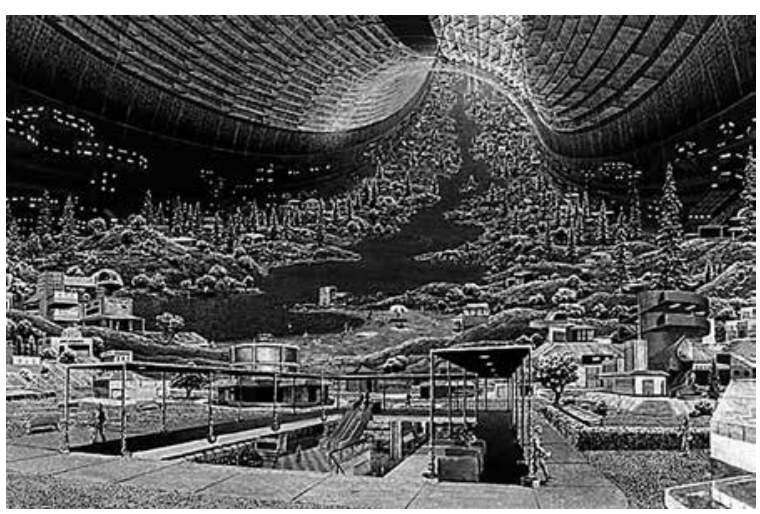

Fonte: Disponível em: http://nerdivinas.com/

Os projetos da época eram bastante fantasiosos, mas constituíam a ideia de uma alternativa de moradia para a humanidade quando o planeta Terra não fosse mais suficiente para abrigá-la.

\section{- gaRRAFA DE KLEIN}

Ao contrario da faixa de Möbius, em que existe uma borda, a Garrafa de Klein (Figura 10) é uma superfície não orientável que não a possui. Foi estudada por Felix Klein no século XX e nela, a ideia de interior e exterior se perde, dando a noção de um objeto único.

Figura 10: Garrafa de Klein

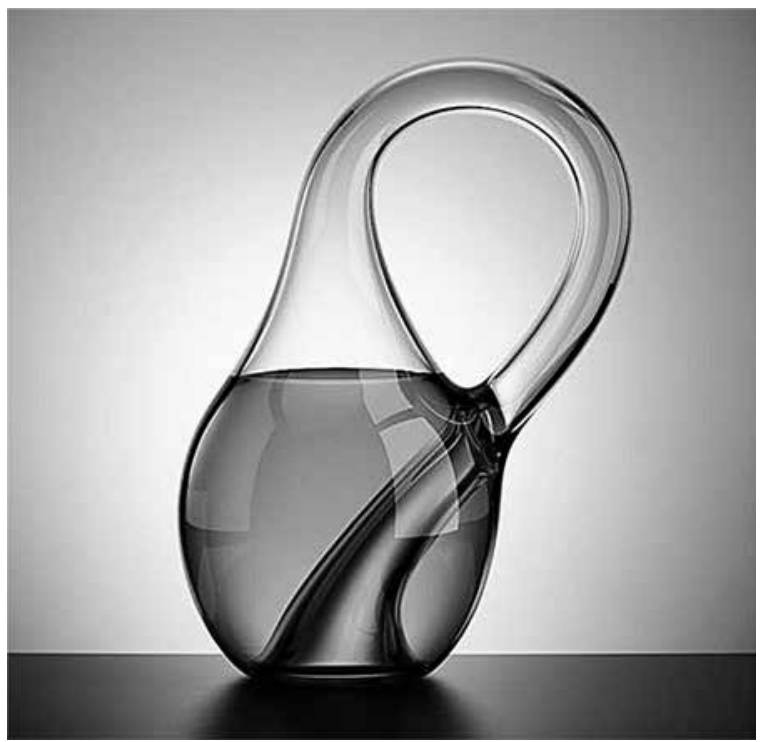

Fonte: Disponível em: http://cadernodemathema.blogspot. com.br/

Um exemplo de uma arquitetura baseada nessa superfície é uma casa de férias localizada na península de Mornington, próximo à Melbourne na Austrália, em 2008 (Figuras 11 e 12).
Figura 11: Casa Garrafa de Klein - Implantação

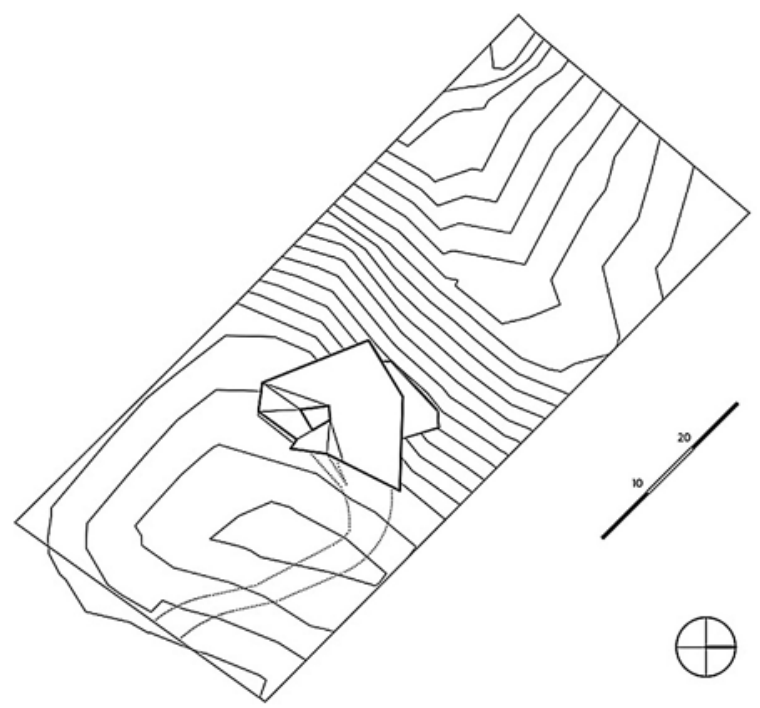

Fonte: Disponível em: http://www.archdaily.com.br/

Figura 12: Casa Garrafa de Klein - Vista interna

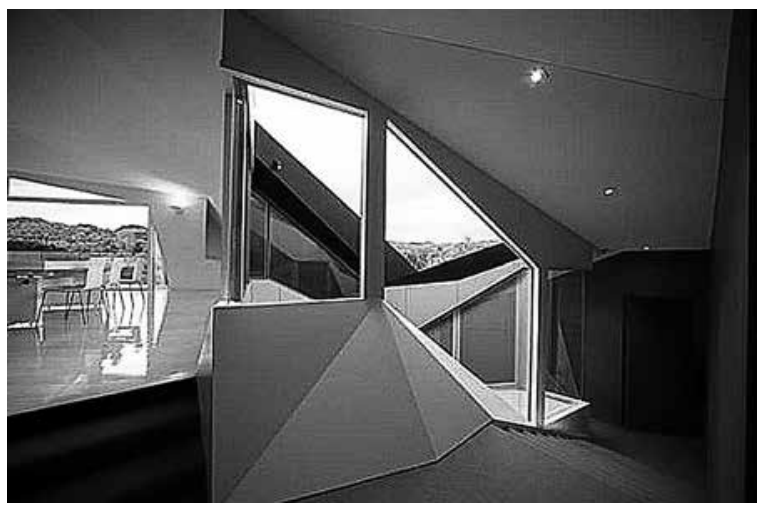

Fonte: Disponível em: http://www.archdaily.com.br/

O conceito inicial partiu de uma concha que logo se desenvolveu para uma estrutura mais complexa: a garrafa de Klein.

A casa se desenrola em torno de um pátio central onde há uma escadaria que conecta todos os ambientes. Ali dentro, os ocupantes têm a sensação de refúgio e distanciamento nos ambientes e, ao mesmo tempo, de proximidade, por estarem inseridos em um meio dinâmico.

\section{Topologia Tipológica}

Ao longo do tempo a tipologia possuiu vários conceito e apropriações, mas sempre se fez necessária manter clara a diferença entre tipo e modelo.

Quatremère de Quincy (século XIX), um teórico francês, foi o responsável por definir o conceito de tipo, diferenciando-o do modelo: "A palavra tipo apresenta menos a imagem de uma coisa a copiar ou imitar por completo que a ideia de um elemento que devia ele mesmo servir de regra 
ao modelo." (QUATREMÈRE DE QUINCY apud PEREIRA, Renata Baesso). Ou seja, O tipo é a ideia por trás da aparência individual do edifício, da qual é possível dar origem à diferentes outros edifícios. Distingue-se, portanto, do modelo que se constitui como um objeto específico que pode ser repetido exatamente como é.

Tratando-se então do viés de maior interesse nesse trabalho, a topologia vai compreender o estudo das relações existentes na forma e sua capacidade de se manter invariável mesmo que seja submetida à deformações. Sendo assim, inserese o conceito de uma arquitetura que, além de ser topológica, se constituirá também como tipológica, ou seja, uma arquitetura capaz de apresentar uma componente de tradição - que mantém um vínculo cultural - e outra inventiva - que vai promover a variedade formal.

A tipologia vai se constituir em alguns aspectos, tais como:

\section{- FUNCIONAL}

Nesse aspecto, o tipo se desenvolve de acordo com a utilização do edifício.

\section{- HOSPITAIS}

Projetos arquitetônicos desenvolvidos para a área da saúde (Figura 13) devem atender diretrizes básicas de acordo com a seção de atendimento específica, com espaços pensados para as áreas de enfermaria, ambulatório, atendimento individualizado, etc.

Figura 13: Hospital Brasília, Brasília

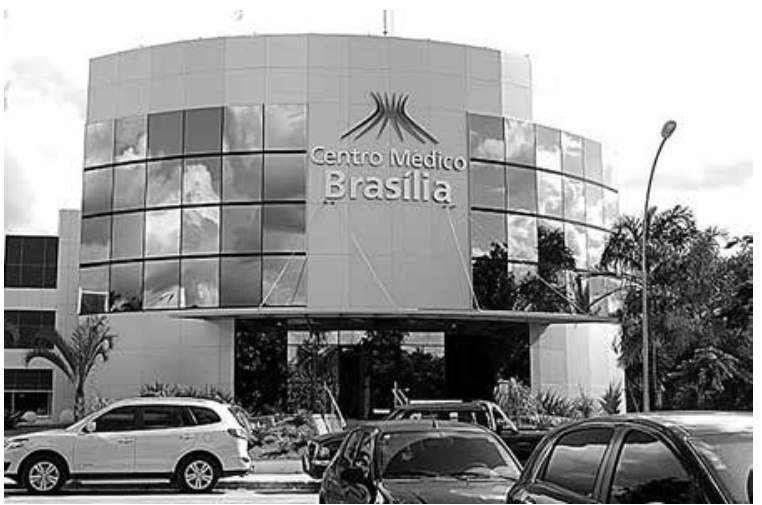

Fonte: Autora

\section{- AEROPORTOS}

Para os aeroportos (Figura 14), faz-se necessária a construção de ambientes diferentes para o uso dos passageiros e para o uso das aeronaves, levando em consideração fluxos, demanda e permanência.
Figura 14: Aeroporto Internacional de Brasília

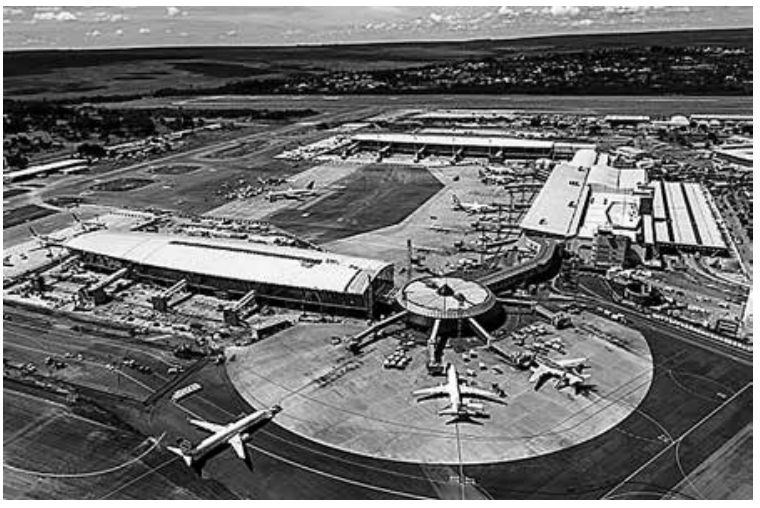

Fonte: Disponível em http://pt.wikipedia.org/

\section{- SHOPPING CENTERS}

Com relação aos shopping centers (Figura 15) a questão do não contato com o ambiente externo deve ser considerada primordial, pois a intenção é manter o consumidor em contato com as lojas e os produtos, diminuindo a sensação do passar das horas.

Figura 15: Shopping Conjunto Nacional, Brasília

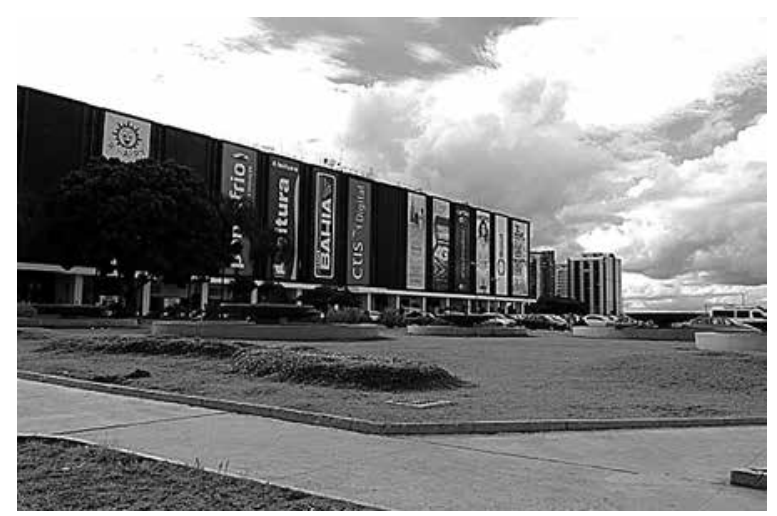

Fonte: Autora

\section{- CENTROS CULTURAIS}

Os centros culturais (Figura 16) seguem uma lógica semelhante à dos shopping centers com relação à separação do ambiente interno e do ambiente externo, apesar de possuírem motivações diferentes: Os centros culturais - e museus - precisam desse isolamento para manterem a integridade das obras ali presentes. 
Figura 16: Centro Cultural Banco do Brasil, Brasília

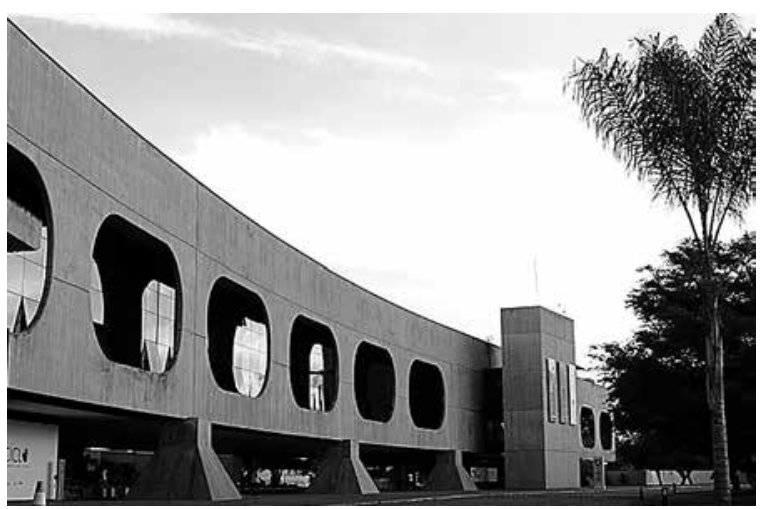

Fonte: Autora

Existe um certo padrão, mas não necessariamente um modelo, de construção para os fins citados acima.

\section{- FORMAL/CONSTRUTIVO}

Aqui, o tipo se dá por questões relacionadas à forma externa e/ou interna da edificação, algo facilmente visualizado nas igrejas dos diferentes períodos da história da arquitetura.

\section{- ROMÂNICO}

As igrejas românicas (Figura 17) eram caracterizadas por possuírem naves abobadadas em pedra, átrio ladeado de pórticos e o seu interior era composto através dos elementos: coluna, feixe de pilares, abóbadas de canhão e tribuna. A planta se dava no formato de uma cruz latina.

Figura 17: Esquema de Igreja Românica

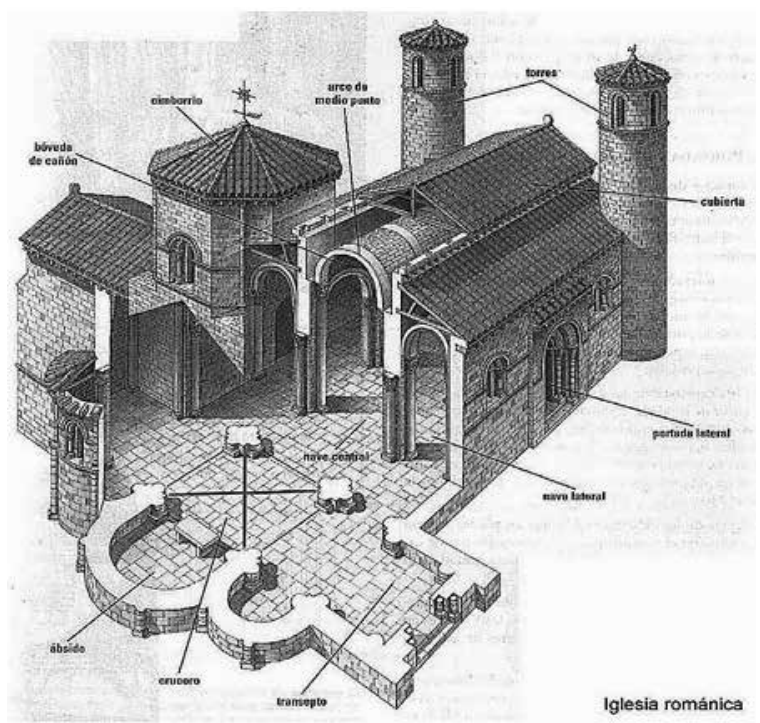

Fonte: https://sumateologica.wordpress.com/

\section{- GÓTICO}

A arquitetura gótica pode ser considerado uma evolução da arquitetura românica. Como forma de melhorar as técnicas utilizadas, surge o arco de ogiva e a abóbada de cruzaria. Geralmente, a fachada principal da igrejas góticas (Figura 18) segue a verticalidade e a leveza enquanto que o seu interior se faz iluminado.

Figura 18: Esquema de Igreja Gótica

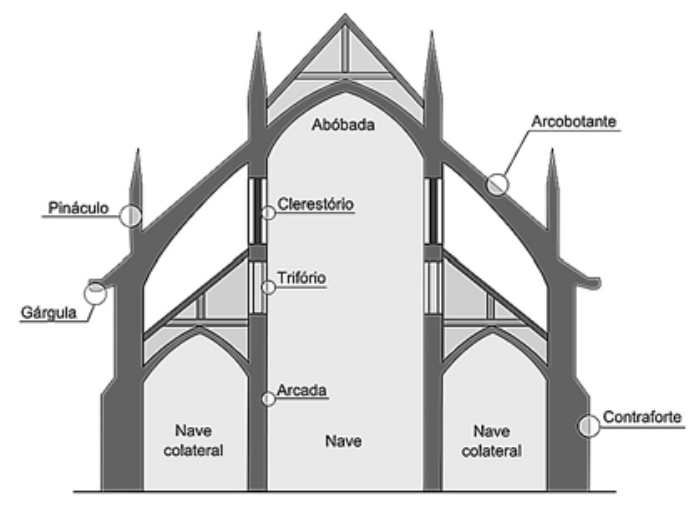

Fonte: https://sumateologica.wordpress.com/

\section{- RENASCENTISTA}

O período renascentista vem para romper o gótico e superar o clássico. Além de tais intuitos serem alcançados por meio de novos usos das abóbadas e cúpulas nas igrejas (Figura 19), a planta se dava no formato de cruz grega e central.

Figura 19: Esquema de Igreja Renascentista

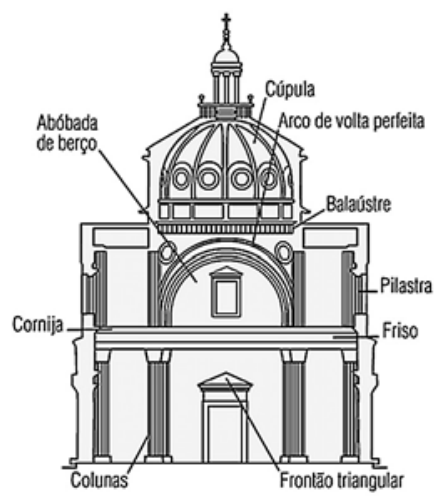

Fonte: http://corpopoietico.blogspot.com.br/

\section{- BARROCO}

Para o período barroco temos, na arquitetura, a associação de elementos retos e curvos (Figura 20). Impõe um dinamismo e uma complexidade organizacional que não deixa o observador parado. Em termos artísticos vai usar a escala como valor plástico de primeira grandeza. 
Figura 20: Detalhamento Barroco no Brasil

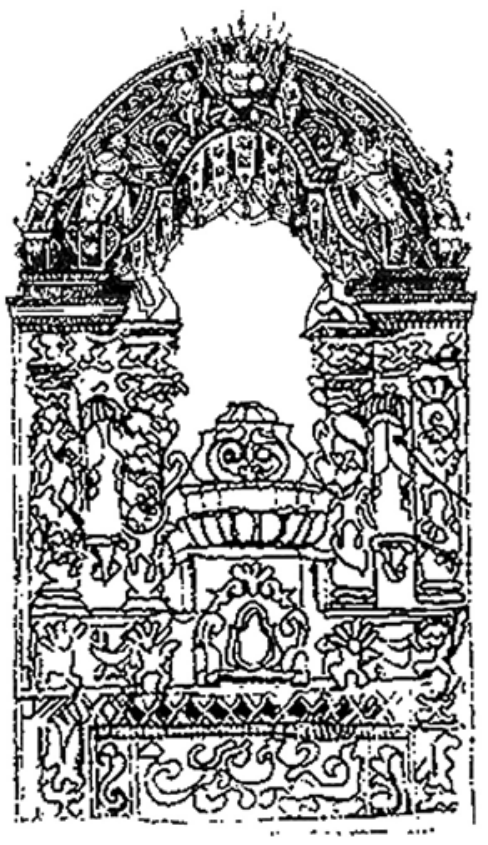

Fonte: http://www.historias.interativas.nom.br/

\section{- NEOCLÁSICO}

A arquitetura neoclássica vai se caracterizar pelo uso de materiais nobres, processos técnicos avançados e sistemas construtivos simples, linhas ortogonais e formas regulares. As igrejas desse período (Figura 21) são marcadas pelo uso de abóbadas de berço ou de aresta, cúpulas monumentais, volumes maciços, frontões triangulares, além da decoração recorrer à um caráter mais clássico.

Figura 21: Esquema de templo Neoclássico

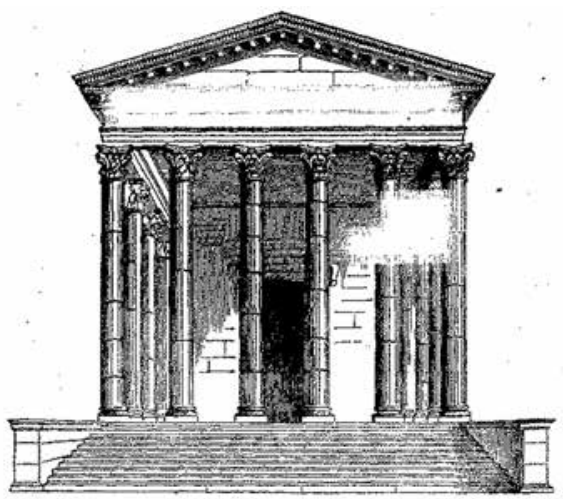

Fonte: http://pt.wikisource.org/

É possível perceber também um certo tipo comum existente nas obras do período modernista, que eram compostas pelos 5 pontos ditados por Le Corbusier: pilotis; terraço-jardim; janelas em fita; fachada livre e planta livre.

Trazendo para o contexto de Brasília, observa-se muito forte essa questão tipológica nos prédios das superquadras (Figuras 22, 23 e 24), no Plano
Piloto, onde existem alguns tipos específicos de projeção dos edifícios.

Figura 22: Habitação - Levantamentos de tipos de projeção (Machado, 2008)

\begin{tabular}{|l|l|l|}
\hline & \multicolumn{1}{|c|}{ Forma } & \multicolumn{1}{|c|}{ Local } \\
\hline Tipo 1 & & $\begin{array}{l}\text { SQS } \\
\text { SQN }\end{array}$ \\
\hline Tipo 2 & & $\begin{array}{l}\text { SQDS } \\
\text { SQDN }\end{array}$ \\
\hline Tipo 3 & & $\begin{array}{l}\text { SQS } \\
\text { SQN }\end{array}$ \\
\hline Tipo 4 & & $\begin{array}{l}\text { SQS, SQN } \\
\text { SQDS, SQDN }\end{array}$ \\
\hline Tipo 5 & & SQS 207 \\
\hline Tipo 6 & & SQS 207 \\
\hline Tipo 7 & $\mathbf{4}$ & SQN 204 \\
\hline
\end{tabular}

Fonte: Disponível em: http://mdc.arq.br/

Figura 23: SQS 411

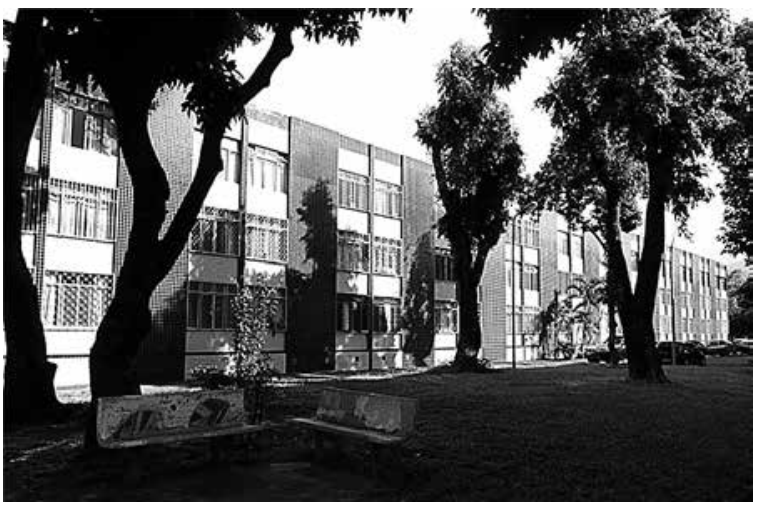

Fonte: Autora

Figura 24: SQS 411

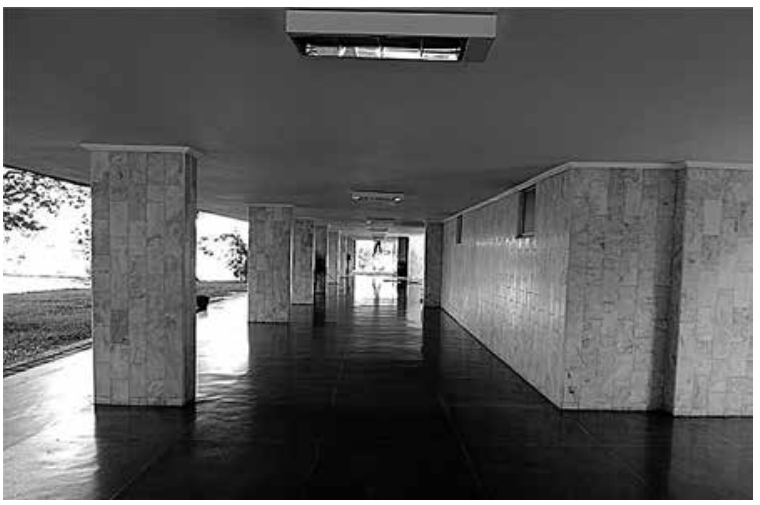

Fonte: Autora

\section{Topologia Singular ou não Tipológi- ca}

Por outro lado, temos a arquitetura dita não tipológica, aquela que não se constitui passível de derivações. 
A primeira fase do Movimento Moderno foi caracterizada por forte rejeição ao uso dos tipos como "instrumento para a compreensão do objeto arquitetônico a partir de sua historicidade [...]" (FILHO, Arthur Campos Tavares, 2005: p. 25). A industrialização da arquitetura, as novas tecnologias e materiais, a produção seriada, tudo isso coloca o projeto arquitetônico possível de ser desenvolvido por meio de um protótipo.

A segunda fase foi marcada pela transformação dessa negação em uma nova espécie de doutrina. Le Corbusier, ao ditar os 5 pontos da arquitetura moderna, eleva o protótipo ao tipo, que permite a geração de formas arquitetônicas.

No entanto, a produção arquitetônica passou a ser traduzida em mera repetição, transformando o significado de tipo em modelo.

Brasília não foge à regra. É uma cidade que foi criada sob preceitos modernistas, idealizada por Lucio Costa e concretizada por Oscar Niemeyer e Joaquim Cardozo.

Apesar de facilmente se encontrar os protótipos dessa arquitetura moderna ao caminhar pelas superquadras, também é possível se deparar com construções que se encaixam na classificação de uma arquitetura topológica que apresenta grande singularidade estrutural e compositiva, tais como a Catedral de Brasília (Figura 25), a Ponte JK (Figura 26), - Palácio da Justiça (Figura27), o Palácio do Planalto (Figura28), o Instituto Central de Ciências (Figura 29) e o Memorial Darcy Ribeiro (Figura 30).

Figura 25: Catedral de Brasília

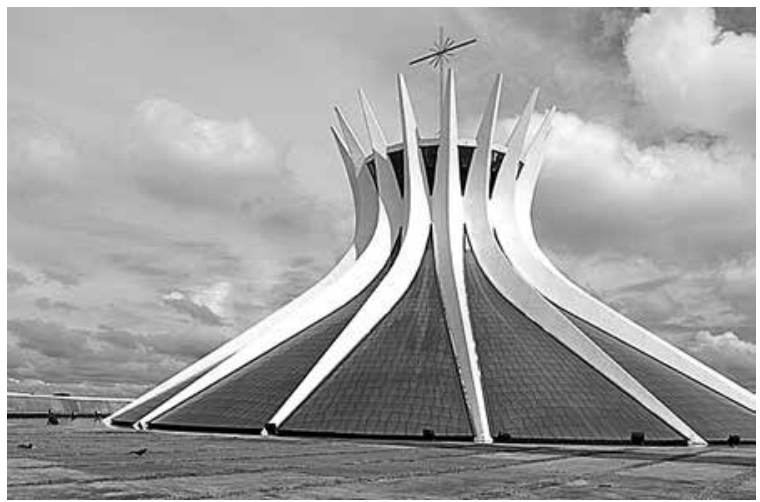

Fonte: Autora
Figura 26: Ponte JK

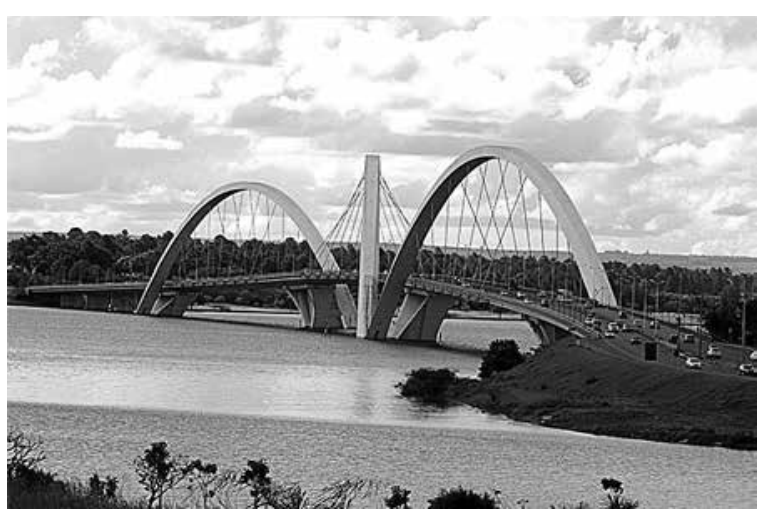

Fonte: Autora

Figura 27: Palácio da Justiça

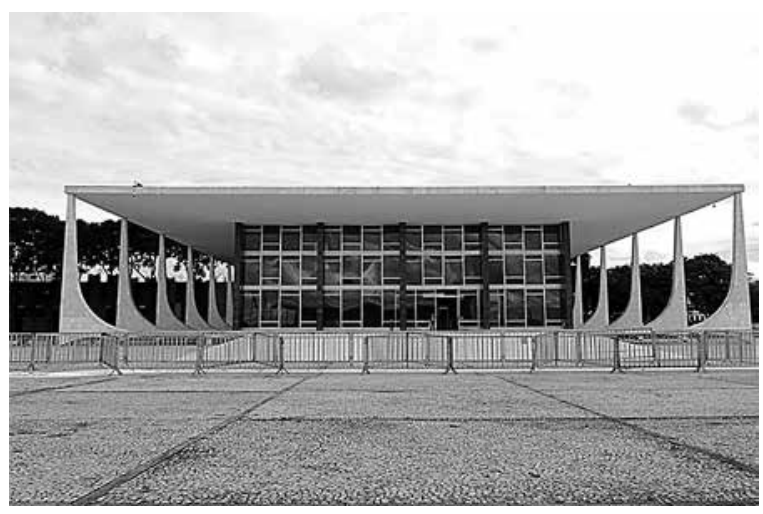

Fonte: Autora

Figura 28: Palácio do Planalto

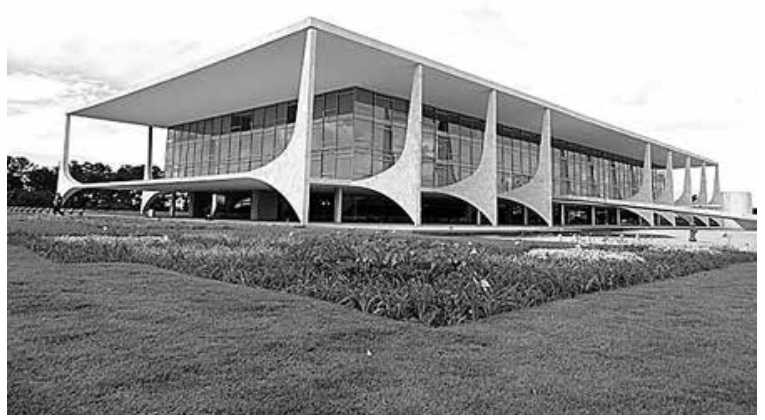

Fonte: Autora

Figura 29: Instituto Central de Ciências

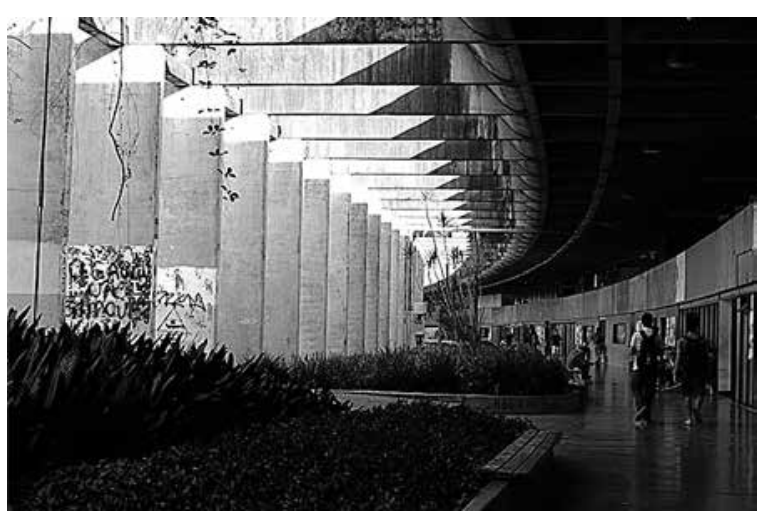

Fonte: Autora 


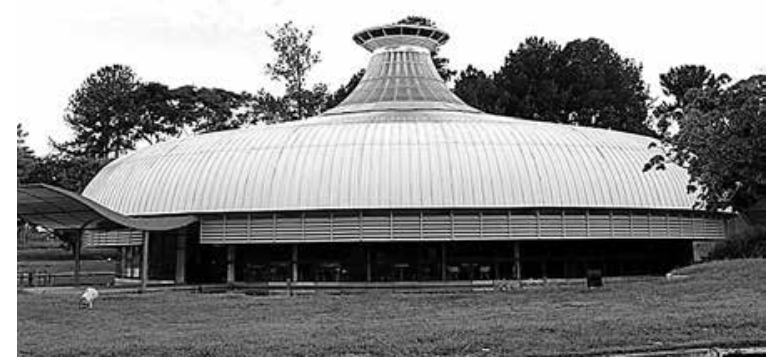

Fonte: Autora

Tais obras carregam um fato característico importante para o aspecto topológico/tipológico: são estruturas perfeitamente únicas compostas a partir de elementos repetidos, garantindo assim sua singularidade.

\section{Conclusão}

De fato, existem interfaces entre a topologia e a arquitetura. Nesse contexto, uma proposição inovadora é utilizada para classificar os principais tipos de topologias arquitetônicas existentes e sua relação com a forma.

Exemplos encontrados no recorte de Brasília-DF são mostrados e sua relação com os aspectos arquitetônicos da época, expostos.

\section{Referências}

CONSIGLIERI, Victor. A morfologia da Arquitetura. (1920-1970). Lisboa, Referência/ Editorial Estampa, 1999. vs. I e II.

ABASCAL, Eunice Helena Sguizzardi Abascal e BILBAO, Carlos Abascal. "Arquitetura e ciência: topologia e intencionalidade em projeto, fronteiras". Arquitextos, São Paulo, v. 137, p. 01-13, 2011.

SPERLING, David Moreno. "Arquiteturas Contínuas e Topologia: Similaridades em Processo". Dissertação de Mestrado. São Paulo: USP, 2003

PEREIRA, Renata Baesso. "Arquitetura, imitação e tipo em Quatremère de Quincy". Tese de Doutorado. São Paulo: USP, 2008.

SAMPAIO, João Carlos V. "Quatro cores e matemática", Salvador, II Bienal da SBM, 2009

FILHO, Arthur Campos Tavares. "Reflexões sobre a Noção de Tipo Morfológico e o Programa Arquitetônico: Os Casos das Escolas Municipais Estados Unidos e República Argentina". Dissertação de Mestrado. Rio de Janeiro: UFRJ, 2005. 